\title{
Aspectos éticos e trâmites da publicação de relato de caso no Brasil
}

\author{
Ethical aspects and procedures for the publication of case reports in Brazil \\ Aspectos éticos y procedimientos para la publicación de informes de casos en Brasil
}

Recebido: 15/02/2021 | Revisado: 18/02/2021 | Aceito: 22/02/2021 | Publicado: 28/02/2021

Estelita Lima Cândido

ORCID: https://orcid.org/0000-0001-9434-2930 Universidade Federal do Cariri, Brasil

E-mail: estelita.lima@ufca.edu.br

Tatianne Régia Gomes Ribeiro

ORCID: https://orcid.org/0000-0001-7188-2002 Universidade Federal do Cariri, Brasil E-mail: tatianne.ribeiro@ufca.edu.br

Maria Auxiliadora Ferreira Brito ORCID: https://orcid.org/0000-0002-9625-0033 Universidade Federal do Cariri, Brasil

E-mail: maria-auxiliadora.brito@ufca.edu.br

Sandhara Ribeiro Rodrigues

ORCID: https://orcid.org/0000-0002-8566-2032 Universidade Federal do Cariri, Brasil

E-mail: sandhara.rodrigues@ufca.edu.br

Maria Darcylene de Souza Feitosa ORCID: https://orcid.org/0000-0002-4896-9545 Secretaria Municipal de Saúde de Barbalha, Brasil E-mail: darcylenemaria0@gmail.com

Francisco Pereira Júnior Feitosa ORCID: https://orcid.org/0000-0003-4552-5516 Secretaria Municipal de Saúde de Barbalha, Brasil E-mail: juniorfpereira@hotmail.com

Jucycler Ferreira Freitas

ORCID: https://orcid.org/0000-0003-4671-6883 Universidade Federal do Cariri, Brasil E-mail: jucyclerferreira@gmail.com

\begin{abstract}
Resumo
A publicação de um relato de caso tem por objetivo transmitir aos outros uma informação nova, relevante, geralmente conduzida por um caminho inabitual. Ele pode gerar um potencial para modificar a prática clínica, ou hipóteses para novos estudos. Mesmo não se tratando de uma pesquisa, é necessário que todos os princípios éticos que visem à proteção do participante sejam respeitados. O presente artigo apresenta as diretrizes para a redação de relatos de caso de acordo com as resoluções e normativas vigentes no Brasil, bem como a tramitação dos mesmos no sistema Comitês de Ética em Pesquisa/Comissão Nacional de Ética em Pesquisa. Tais informações são oportunas na medida em que norteiam pesquisadores e Comitês de ética em pesquisas com seres humanos.
\end{abstract}

Palavras-chave: Ética; Ética em pesquisa; Relatos de casos.

\begin{abstract}
The publication of a case report is intended to convey to others a new, relevant information, usually driven by an unusual path. It can generate a potential for changing clinical practice or hypotheses for new studies. Even if it is not research, all ethical principles that aim at the protection of the participant must be respected. This article presents the guidelines for writing case reports in accordance with the resolutions and regulations in force in Brazil, as well as their processing in the Research Ethics Committees / National Commission of Ethics in Research. Such information is timely as it guides researchers and ethics committees for research involving humans.
\end{abstract}

Keywords: Ethics; Ethics research; Case reports.

\section{Resumen}

El propósito de publicar un informe de caso es transmitir información nueva y relevante a otras personas, generalmente realizada de una manera inusual. Puede generar potencial para modificar la práctica clínica o hipótesis para estudios posteriores. Aunque esto no es una investigación, es necesario que se respeten todos los principios éticos que protegen al participante. Este artículo presenta los lineamientos para la elaboración de informes de casos de acuerdo con las resoluciones y normativas vigentes en Brasil, así como su procesamiento em el sistemas Comité de 
Ética en Investigación/Comité Nacional de Ética en Investigación. Esta información es oportuna ya que guía a los investigadores y comités de ética en la investigación con seres humanos.

Palabras clave: Ética; Ética de la investigación; Reportes del caso.

\section{Introdução}

A pesquisa é um meio primordial para uma educação dinâmica, visto que é através dela que se produzem novos conhecimentos (Vieira \& Vieira, 2020). Para a saúde, a pesquisa é justificada pela necessidade constante de gerar novas informações que permitam o melhoramento e a efetividade das formas de proteção, bem como de promoção da saúde e redução das doenças (Brasil, 2007).

A pesquisa com seres humanos é dotada de particularidades éticas pautadas nos princípios éticos da bioética: autonomia, não maleficência, beneficência, justiça e equidade, dentre outros (Brasil, 2013). Seja a pesquisa realizada com dados primários ou secundários, os mesmos devem ser respeitados. Cujos dados primários referem-se ao fato de não terem sido antes coletados e servem para o atendimento das necessidades peculiares da pesquisa em andamento. Doutra banda, os secundários dizem respeito aos dados que já foram coletados, passaram pelo processo de tabulação e ordenação, em algumas circunstâncias já estando analisados e catalogados à disposição de quem possua interesse (Crescitelli, Custódia de Oliveira, Futino Barreto, 2007).

No Brasil, a realização de pesquisas que envolvem seres humanos tanto na área biomédica, como das Ciências Humanas e Sociais, está sujeita à aprovação de órgãos responsáveis pela avaliação de seus aspectos éticos. O maior deles é a Comissão Nacional de Ética em Pesquisa (Conep), instância colegiada, de natureza consultiva, deliberativa, normativa, educativa e independente, vinculada ao Conselho Nacional de Saúde/MS (Brasil, 2013). Sua finalidade é elaborar e atualizar as diretrizes e normas para a proteção dos participantes de pesquisa, bem como coordenar a rede de Comitês de Ética em Pesquisa (CEP) das instituições vinculadas ao Sistema CEP/Conep (Brasil, 2020).

O objetivo do estudo é descrever os aspectos éticos que devem ser respeitados para a condução e publicação de relatos de caso no Brasil.

\section{Metodologia}

Trata-se de uma pesquisa de natureza básica, descritiva e documental (Prodanov, 2013). A pesquisa documental é caracterizada pela coleta e análise de dados provenientes de documentos públicos ou privados, escritos ou não, constituindo o que se denomina de fontes primárias (Marconi \& Lakatos, 2003). Ela se diferencia da pesquisa bibliográfica porque o material analisado não recebeu tratamento analítico, podendo ser reelaborado de acordo com os objetos da pesquisa (Gil, 2002).

Os documentos analisados neste estudo são de fontes públicas, constituindo-se de resoluções e outras normativas do Conselho Nacional de Saúde e da Conep, em especial a Carta circular 166/2018 que apresenta as normas para a condução e publicação de relatos de caso para a área biomédica.

\section{Resultados e Discussão}

O relato de caso é uma "Modalidade de estudo na área biomédica com delineamento descritivo, sem grupo controle, de caráter narrativo e reflexivo, cujos dados são provenientes da prática cotidiana ou da atividade profissional. Portanto, no momento de sua elaboração, os eventos narrados estarão consumados, não estando previstos experimentos como objeto do estudo" (Brasil, 2018). Esse tipo de estudo é tido como um relevante manancial de informações, que em sua maioria é excluído ou esquecido das grandes pesquisas multicêntricas (Yoshida, 2007). 
Em relação ao número de casos relatados, alguns autores consideram que até quatro casos o estudo ainda é classificado como relato de caso. Contudo, se o número for superior ele passa a ser considerado uma série de casos (AbuZidan; Abbas \& Hefny, 2012).

A publicação de um relato de caso tem por objetivo transmitir aos outros uma informação nova, relevante, geralmente conduzida por um caminho inabitual. Ele pode gerar um potencial para modificar a prática clínica, ou mesmo hipóteses para novos estudos. É pertinente em patologias raras ou de apresentação inusitada, em intervenções pioneiras ou quando a intervenção tem um desfecho incomum (Barroso, 2016). A eles ainda pode ser adicionada uma revisão de literatura, modalidade que enriquece a narração, pois permite que o autor apresente o estado da arte sobre o estudo em tema e compare suas observações com as de outros estudos.

Embora se trate da narração de um estado mórbido e sua evolução com base em dados secundários, os prontuários e demais documentos dos sistemas de saúde associados ao caso, a publicação do relato não pode ocorrer sem a aprovação de um CEP. Para tanto, os relatos de caso devem respeitar preceitos relacionados à privacidade dos participantes, à confidencialidade dos dados e a dignidade humana (Brasil, 2018). Cuja dignidade trata-se de um princípio fundamental, resguardado no artigo $1^{\circ}$ da Constituição Federal de 1988 (Brasil, 1988).

Os interessados em publicar um relato de caso devem se cadastrar na Plataforma Brasil, um sistema gerido pela Conep que encaminhará o projeto ao CEP ao qual o pesquisador está vinculado, ou para o mais próximo dele, quando não há declaração de vínculo em seu cadastro.

Os CEP recebem apenas projetos de pesquisa, sendo o relato de caso, a exceção, dadas as suas características de obtenção dos dados. Nessa condição, o relator pode encaminhar o seu protocolo na modalidade "Projeto de pesquisa" (mesmo já tendo finalizado) ou no formato da publicação "Relato de caso". Ao protocolo devem ser anexados o Termo de Consentimento Livre e Esclarecido (TCLE) e Termo de Assentimento (TALE), se necessário, o relato ou o projeto de relato, autorizações para uso de imagem, se houver, além da autorização das instituições detentoras dos documentos consultados.

Segundo a Res CNS 466/12, o TCLE é definido como a "a anuência do participante da pesquisa e/ou de seu representante legal, livre de vícios (simulação, fraude ou erro), dependência, subordinação ou intimidação, após esclarecimento completo e pormenorizado sobre a natureza da pesquisa, seus objetivos, métodos, benefícios previstos, potenciais riscos e o incômodo que esta possa acarretar" (Brasil, 2013). O mesmo conceito se estende ao TALE, sendo o participante criança, adolescente ou legalmente incapaz.

Até a publicação da Carta circular 166/2018, as diretrizes para a tramitação dos relatos de caso no sistema CEP/Conep ainda não estavam estabelecidas. O documento também versa sobre a redação do texto, evitando que informações consideradas antiéticas sejam expostas na publicação. As orientações da Carta estão amparadas em outros documentos anteriores a ela, como o Código de Ética Médica e a Resolução CNS 466/16. A necessidade de obtenção do consentimento do paciente está prevista no Capítulo 12, artigo 101 do novo Código de Ética Médica (CFM, 2019). No momento da submissão de um relato de caso em um CEP, no formato de publicação, já é necessário que o TCLE esteja assinado pelo paciente ou responsável legal. Na impossibilidade de obtenção do TCLE e TALE (quando for o caso), o pesquisador deve solicitar a dispensa de aplicação do termo apresentando justificativa pertinente assinada pelo mesmo, cabendo ao CEP avaliar o mérito da questão (Brasil, 2018).

É válido salientar que o TCLE e o assentimento, quando necessário, exibirá todas as informações necessárias sobre a pesquisa, descritas de forma clara e objetiva, acessível ao provável participante (Brasil, 2013). Este termo, obrigatoriamente, conterá o nome completo da pesquisa e uma redação em formato de convite, evidenciando o motivo para a publicação do relato de caso, as garantias relacionadas à confidencialidade, privacidade e, quando necessário, uso da imagem do participante. A autorização para este último procedimento pode estar contida no TCLE ou em documento separado, preservando-se a autoria de quem coletou a imagem (Brasil, 2018). 
Qualquer informação que possibilite a identificação deve ser evitada, tais como: nome, codinome, iniciais, registros individuais, informações postais, números de telefone, endereços eletrônicos, fotografias, figuras, características morfológicas, entre outros. Desse modo, "A confidencialidade e o respeito à privacidade constituem preceitos morais tradicionais das profissões de saúde, indicando o dever de guarda e reserva em relação aos dados de terceiro, a que se tem acesso em virtude do exercício da atividade laboral” (Villas-Bôas, 2015).

Sobre essa questão, segundo o novo Código de Ética Médica, é vedado ao médico "Fazer referência a casos clínicos identificáveis, exibir pacientes ou imagens que os tornem reconhecíveis em anúncios profissionais ou na divulgação de assuntos médicos em meios de comunicação em geral, mesmo com autorização do paciente" (CFM, 2019).

De acordo com a Carta Circular no 166/2018 o relato de caso não é isento de riscos, podendo ocorrer quebra da confidencialidade. Esta pode trazer danos, materiais e morais, ao participante e a terceiros. Desta forma, todos os riscos devem estar previstos nos TCLE e TALE, bem como suas formas de minimizá-los, além de assegurar ao participante o direito à assistência integral e gratuita, pelo tempo que for necessário, além do direito de buscar indenização.

\section{Considerações Finais}

Relatos e séries de casos são integrantes importantes da literatura médica e continuam a ter seus espaços nas publicações médicas. Por vezes, eles são a primeira evidência de novas doenças e ou de novas terapêuticas. Apesar de relatos e séries de caso ocuparem posições hierarquicamente inferiores em relação a evidências de estudos como ensaios clínicos, são eticamente aceitáveis, desde que respeitados os preceitos relacionados à privacidade dos participantes, à confiabilidade dos dados e à dignidade humana.

Nesse contexto, os esclarecimentos acerca da tramitação dos estudos do tipo "relato de caso" no Sistema CEP/Conep para a área biomédica, são oportunos na medida em que norteiam pesquisadores e Comitês de ética em pesquisas com seres humanos.

É indispensável a contínua realização de estudos e publicação sobre os aspectos éticos que envolvem a pesquisa com seres humanos, seja com dados secundários ou primários, pois é a partir do conhecimento que se buscará cumprir os deveres de pesquisador e respeito aos direitos dos participantes.

\section{Referências}

Abu-Zidan, F. M., Abbas, A. K., Hefny, A. F. (2012). Clinical “case series": a concept analysis. Afr Health Sci. 12(4), 557-62. http://dx.doi.org/10.4314/ahs.v12i4.25.

Barroso R. (2016). Relatos de caso: para além das normas, a coerência e a congruência. Rev Port Med Geral Fam, Lisboa. 32(4), 238-40.

Brasil. Constituição (1988). Constituição da República Federativa do Brasil. Brasília, DF: Senado Federal: Centro Gráfico, 1988.

Brasil (2007). Ministério da Saúde. Secretaria de Ciência, Tecnologia e Insumos Estratégicos. Departamento de Ciência e Tecnologia. Por que pesquisa em saúde? Série B. Textos Básicos de Saúde/Série Pesquisa para Saúde: Textos para Tomada de Decisão. Ministério da Saúde, 2007. 20 p.

Brasil. Conselho Nacional de Saúde. (2013). Resolução no 466, de 12 de dezembro de 2012. Diário Oficial da União. 13 jun. 2013.1 (112), 59-62.

Brasil. (2018). Comissão Nacional de Ética em Pesquisa. Conselho Nacional de Saúde. Carta Circular nº 166/2018.

Brasil. (2020). Conselho Nacional de Saúde. Comissão Nacional de Ética em Pesquisa. Brasília; 2020. http://conselho.saude.gov.br/comissoes-cns/conep/.

CFM. (2019). Resolução CFM n 2.217, de 27 de setembro de 2018. Código de Ética Médica - CFM. - Brasília: Conselho Federal de Medicina, 2019. 108 p.

Crescitelli, E., Oliveira, É. C. D., \& Barreto, I. F. (2006). A internet como fonte informacional para o SIM: os processos de captação e as formas de avaliação. JISTEM-Journal of Information Systems and Technology Management, 3(3), 347-369.

Gil, A. C. (2002). Como elaborar projetos de pesquisa, 4, 175. Atlas.

Marconi, M. D. A., \& Lakatos, E. M. (2003). Fundamentos de metodologia científica. (5a ed.), Atlas. 
Research, Society and Development, v. 10, n. 2, e57310212969, 2021

(CC BY 4.0) | ISSN 2525-3409 | DOI: http://dx.doi.org/10.33448/rsd-v10i2.12969

Prodanov, C. C., \& de Freitas, E. C. (2013). Metodologia do trabalho científico: métodos e técnicas da pesquisa e do trabalho acadêmico. (2a ed.), Editora Feevale.

Vieira, M. M. M., \& Vieira, J. d. A. (2020). Princípio educativo ensino com pesquisa na formação inicial de professores: Perspectivas e desafios. Research, Society and Development, $9(5)$.

Villas-Bôas, M. E. (2015). The right and duty of secrecy, as a patient protection. Revista Bioetica, 23(3).

Yoshida, W. B. (2007). Redação do relato de caso. Jornal Vascular Brasileiro, 6(2), 112-113. 